\title{
Folgen früher Traumatisierung aus neurobiologischer Sicht
}

\author{
Tanja M. Brückl ${ }^{1}$ Elisabeth B. Binder ${ }^{1,2}$
}

Eingegangen: 9. Januar 2017 / Angenommen: 23. Februar 2017 / Online publiziert: 28. März 2017

(c) Der/die Autor(en) 2017. Dieser Artikel ist eine Open-Access-Publikation.

Zusammenfassung Der Zusammenhang zwischen frühen Traumatisierungen in der Kindheit und einem erhöhten psychischen Erkrankungsrisiko ist in der Fachliteratur seit Langem gut belegt. Erst in den letzten Jahren beginnen wir aufgrund technologischer Fortschritte zu verstehen, wie frühe Traumatisierungen körperlich niedergeschrieben werden und sich so ein Leben lang auf verschiedene Aspekte unseres Verhaltens und Erlebens auswirken können. In der vorliegenden Übersicht wird zunächst der aktuelle Erkenntnisstand zu den neurobiologischen Auswirkungen von Kindheitstraumata kurz zusammengefasst. Danach werden genetische und epigenetische Faktoren als mögliche Mechanismen der biologischen Einbettung betrachtet.

Schlüsselwörter Kindheitstrauma - Missbrauch · Misshandlung · Neurobiologie · HPA-Achse - Epigenetik · DNA-Methylierung

\section{Sequelae of early trauma from a neurobiological perspective}

Abstract Childhood trauma is one of the most well-established risk factors for the development of mental disorders. Due to the availability of new technologies, we are now

Tanja M. Brückl

brueckl@psych.mpg.de

1 Abteilung für Translationale Forschung, Max-Planck-Institut für Psychiatrie, Kraepelinstr. 2-10, 80804 München, Deutschland

2 Dept. of Psychiatry and Behavioral Sciences, Emory University School of Medicine, Atlanta, Vereinigte Staaten von Amerika beginning to understand how early trauma gets under the skin and exerts a sustained influence on various domains of psychological functioning and health. In the present review we will first briefly summarize what is currently known about the neurobiological effects of childhood trauma. We will then consider genetic and epigenetic factors as possible mechanisms mediating the biological embedding of childhood trauma.

Keywords Childhood trauma - Abuse - Maltreatment · Neurobiology · HPA axis · Epigenetics · DNA methylation

\section{Einleitung}

Kindheitstraumata gelten mittlerweile als einer der gesichertsten Risikofaktoren für die Entwicklung psychischer Störungen im späteren Leben. In epidemiologischen Studien zeigen sich weltweit bei Teilnehmern mit Traumaexposition in der Kindheit signifikant erhöhte Lebenszeitprävalenzen nahezu jeder psychischen Störung im Vergleich zu Probanden ohne Kindheitstrauma. Fast 30\% aller psychischen Störungen sind den Schätzungen dieser Studien zufolge auf Kindheitstrauma und andere widrige Kindheitsumstände zurückzuführen (Kessler et al. 2010). Kindheitstraumata gehen aber auch mit einem erhöhten Risiko für physische Erkrankungen wie z. B. Herz- und Autoimmunerkrankungen einher (z. B. Goodwin und Stein 2004).

Ein Erklärungsmodell für den weitreichenden und lebenslangen Einfluss früher Traumatisierungen besagt, dass Kindheitstraumata Veränderungen in neurobiologischen Systemen induzieren, die wiederum die Vulnerabilität für Erkrankungen erhöhen (biologische Einbettungshypothese). Die meisten neurobiologischen Systeme sind zum Zeitpunkt der Geburt noch nicht ausgereift. Anhaltende 


\begin{tabular}{|c|c|c|}
\hline \multicolumn{2}{|r|}{ Auswertungsebenen - Kindheitstrauma } & \multirow[b]{2}{*}{$\begin{array}{l}\text { Genetik } \\
\text { Moderator } \\
\text { (Halldorsdottir und } \\
\text { Binder 2017) }\end{array}$} \\
\hline 0 & $\begin{array}{l}\text { SNP/DNA -Varianten } \\
\text { Genetische Faktoren als Moderatoren des Einflusses von } \\
\text { Kindheitstraumata auf die AVs der Ebenen 1-4 } \\
\text { • } \\
\text { HPA-Achsen Gene: NR3CI, FKBP5 (Zannas und } \\
\text { Binder 2014) } \\
\text { - Serotonerges System: 5-HTTLPR (Sharpley et al. } \\
\text { 2014); MAOA (Byrd und Manuck 2014) } \\
\end{array}$ & \\
\hline & $\begin{array}{l}\text { Kindheitstrauma } \\
\text { sexueller, physischer und emotionaler Missbrauch } \\
\text { physische und emotionale Vernachlässigung, } \\
\text { Verlust eines Elternteils durch Tod/Trennung }\end{array}$ & $\begin{array}{l}\text { Umwelt } \\
\text { UV }\end{array}$ \\
\hline & ク ク ク & 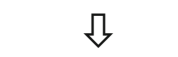 \\
\hline & $\begin{array}{l}\text { DNA-Methylierung } \\
\text { genomweit und von Kandidatengenen, z.B. NR3Cl (Turecki } \\
\text { und Meaney 2016); FKBP5 (Zannas et al. 2016) 5-HTTLPR } \\
\text { (Palma-Gudiel und Fananas 2017; Provenzi et al. 2016) in } \\
\text { Nervenzellen und peripheren Blutzellen } \\
\text { Telomere (Price et al. 2013) }\end{array}$ & $\begin{array}{l}\text { Epigenetik / } \\
\text { Telomere } \\
\text { AV/ } \\
\text { Mechanismus } \\
\text { (Mediator) } \\
\text { (Blaze et al. 2015) } \\
\end{array}$ \\
\hline 2 & $\begin{array}{l}\text { Endokrines System (Fehlregulation der HPA-Achse: Heim } \\
\text { et al. 2008) } \\
\text { Immunsystem (C-reaktives Protein, CRP; Interleukine: } \\
\text { Coelho et al. 2014) } \\
\text { Neuronale Prozesse/ZNS/Gehirnentwicklung } \\
\text { (Übersicht über Bildgebungsstudien bei Teicher und Samson } \\
\text { 2016) }\end{array}$ & $\begin{array}{l}\text { Neuro- } \\
\text { biologische } \\
\text { Systeme } \\
\text { AV } \\
\text { (Danese und } \\
\text { McEwen 2012; De } \\
\text { Bellis und Zisk } \\
\text { 2014; McCrory et } \\
\text { al. 2011; Nemeroff } \\
\text { 2016) } \\
\end{array}$ \\
\hline & $\begin{array}{l}\text { Verhalten (sozial, kriminell, aggressiv) } \\
\text { Emotionen und Emotionsregulation } \\
\text { Kognitionen } \\
\text { Persönlichkeit }\end{array}$ & $\begin{array}{l}\text { Psychische } \\
\text { Funktions- } \\
\text { bereiche/ } \\
\text { AV }\end{array}$ \\
\hline & $\begin{array}{l}\text { Psychische Störungen } \\
\text { Substanzstörungen } \\
\text { Physische Erkrankungen }\end{array}$ & $\begin{array}{l}\text { Erkrankungen } \\
\text { AV }\end{array}$ \\
\hline
\end{tabular}

Abb. 1 Auswertungsebenen von Studien zu den Auswirkungen von Kindheitstraumata. $A V$ abhängige Variable, SNPs Single Nukleotid Polymorphismen, $U V$ Unabhängige Variable/Faktor, ZNS Zentrales Nervensystem. Literaturangaben in Klammern verweisen auf Übersichtsarbeiten, systematische Reviews und Metaanalysen zu dem jeweiligen Thema

Traumata während sensibler Entwicklungsphasen greifen vermutlich in Reifungsprozesse ein und verändern dadurch langfristig die Funktionsweise neurobiologischer Systeme (Heim und Binder 2012).

Die vielfältigen Auswirkungen von Kindheitstraumata wurden in einer Fülle von Studien beschrieben, die sich anhand ihres Auswertungsschwerpunktes in verschiedene Gruppen einteilen lassen (Abb. 1). Neuere Studien konzentrieren sich vermehrt auf die unmittelbare biologische Wirkung von Traumata (Ebene 1 in Abb. 1, proximale, dem biologischen Mechanismus nahestehende Faktoren, wie z. B. DNA-Methylierung), während frühere Studien oftmals distale Auswirkungsfaktoren betrachteten (Ebene 4 in Abb. 1, z. B. Erkrankungen).

Im Folgenden fassen wir den aktuellen Erkenntnisstand zu den neurobiologischen Auswirkungen von Traumata in der Kindheit kurz zusammen und gehen dann ausführli- cher auf (epi)genetische Prozesse als mögliche Übertragungsmechanismen ein. Der Schwerpunkt liegt hierbei auf genetischen Befunden zum Stresshormonsystem. Da es aus Platzgründen nicht möglich ist, auf alle Studien aus diesem Bereich (Ebenen 0-2 in Abb. 1) einzugehen, werden bevorzugt Ergebnisse von Übersichtsartikeln und anderen ausgewählten Studien dargestellt. Auf weiterführende Übersichtsartikel wird in Abb. 1 verwiesen.

\section{Neurobiologische Korrelate von Kindheitstraumata}

Nahezu alle Studien betrachten Kindheitstraumata als eine Form von Umweltstress, der eine biologische Stressantwort auslöst. Die Hypothalamus-Hypophysen-Nebennierenrinden-Achse (,hypothalamic-pituitary-adrenal [HPA] axis“) ist deswegen das am besten untersuchte neurobiologische System im Zusammenhang mit Kindheitstraumata.

Beschreibung der HPA-Achse: Bei Aktivierung der HPA-Achse (z. B. in Bedrohungssituationen) werden im Hypothalamus das Kortikotropin-Releasing-Hormon (CRH) und Vasopressin (AVP) ausgeschüttet. CRH und AVP binden daraufhin in der Hypophyse an ihre spezifischen Rezeptoren CRHR1 und V1b, wodurch die Bildung des adrenokortikotropen Hormons (ACTH) stimuliert wird. ACTH wiederum löst in der Nebennierenrinde die Herstellung und Freisetzung von Glukokortikoiden (z. B. Cortisol) aus. Glukokortikoide haben ein breites physiologisches Wirkspektrum; sie führen u. a. zur Mobilisierung von Glucose aus Energiespeichern, erhöhen die kardiovaskuläre Aktivität, dämpfen das Immunsystem und unterstützen kurzfristig die Anpassung des Organismus an die Stresssituation. Glukokortikoide wirken über negative Feedback-Schleifen auf das System zurück. Die Synthese und Ausschüttung von CRH im Hypothalamus und von ACTH in der Nebennierenrinde und somit die Aktivierung der HPA-Achse werden durch die Anbindung von Glukokortikoiden an Glukokortikoidrezeptoren (GR) beendet (Holsboer 2000). Binden sich Glukokortikoide an den GR, verändert dieser seine Gestalt und kann dann an sog. glukokortikoidresponsive Elemente (GRE) der DNA binden, wodurch die Expression nahe gelegener Gene moduliert wird. Der GR wird somit durch die Anbindung des Liganden zum Transkriptionsfaktor (de Kloet et al. 2005).

Wiederholter Nachweis einer Fehlregulation der HPAAchse bei in der Kindheit misshandelten Personen: Zahlreiche Studien beobachteten bei misshandelten Kindern und Erwachsenen, die retrospektiv von Misshandlung in der Kindheit berichten, eine Fehlregulation der HPA-Achse. Allerdings deuten die Ergebnisse dieser Studien nicht 
immer in die gleiche Richtung, und Kindheitstraumata wurden sowohl mit einer Hyper- als auch Hypoaktivität der HPA-Achse in Verbindung gebracht (detailliert zusammengefasst in De Bellis und Zisk 2014; Danese und McEwen 2012; Heim et al. 2008). Nach Danese und McEwen (2012) zeigen v. a. Studien, die psychisch Erkrankte untersuchen, eine signifikante Assoziation zwischen Kindesmisshandlung und Merkmalen einer gesteigerten HPA-Aktivität, wie z.B. erhöhte Cortisolwerte, erhöhte CRH-Konzentrationen in der Zerebrospinalflüssigkeit (CSF), stärkere Cortisolantwort auf einen psychosozialen Stresstest sowie eine geringere Unterdrückung der Cortisolantwort nach Gabe eines synthetischen Glukokortikoids (Dexamethason, DEX) in Kombination mit CRH (DEX/CRH-Test). Demgegenüber stehen Studien, die niedrigere basale Cortisolwerte sowie eine abgeschwächte Cortisolantwort in Reaktion auf den DEX/CRH-Test oder einen psychosozialen Belastungstest bei größtenteils gesunden Personen mit Kindesmisshandlung im Vergleich zu nichtmisshandelten Kontrollen berichten (Danese und McEwen 2012). Es gibt auch einzelne Studien an misshandelten Kindern, die keine HPA-Achsen-Auffälligkeiten beobachteten (z. B. De Bellis et al. 1994; Kaufman et al. 1997). Viele Faktoren kommen als Erklärung für die inkonsistenten Ergebnisse infrage. Je nach Art und Dauer des Traumas, Alter zum Zeitpunkt der Traumatisierung, Vorliegen von psychischen Störungen und zusätzlichen Traumata können sich andere Zusammenhänge zwischen Kindheitstrauma und HPA-AchsenAktivität ergeben (Nemeroff 2016). Einen wichtigen Faktor stellt auch die Zeit dar, die seit dem Trauma vergangen ist, und damit verbundene physiologische Habituationsprozesse. Eine der wenigen Longitudinalstudien auf dem Gebiet ergab, dass die zunächst erhöhten morgendlichen Cortisolwerte bei sexuell missbrauchten Mädchen mit zunehmendem Alter und zeitlichem Abstand zum Trauma abnehmen und im Erwachsenenalter unter die Werte einer nichttraumatisierten Vergleichsgruppe fallen (Trickett et al. 2010).

\section{Elterliche Feinfühligkeit und sichere Eltern-Kind-Bin-} dung als Stresspuffer: Eine sichere Bindung an zumindest einen Elternteil (z. B. ein Elternteil misshandelt, zu dem anderen besteht aber eine sichere Bindung) könnte die schädigenden Auswirkungen von Kindheitstraumata abfedern und ebenfalls erklären, warum ein Kindheitstrauma unterschiedliche Auswirkungen auf das Stresshormonsystem hat. Studien an gesunden nichtmisshandelten Kindern zeigen z.B., dass sich hohe mütterliche Feinfühligkeit dämpfend auf die HPA-Achsen-Aktivität des Kindes in Stresssituationen auswirkt (z. B. Albers et al. 2008). Man vermutet, dass in den ersten Lebensjahren die Eltern-KindInteraktion die Rolle eines externen Regulators der HPAAchse des Kindes einnimmt (Gunnar und Donzella 2002).
Fällt dieser soziale Regulator aus, weil z. B. der Missbrauch von den Eltern ausgeht, könnte es zu einem Glukokortikoidanstieg beim Kind kommen, der womöglich während der Entwicklung stressempfindlicher Gehirnregionen (z. B. Hippocampus) eine Fehlregulation herbeiführt.

Vereinzelte Hinweise auf veränderte Oxytozinkonzentrationen bei misshandelten Personen: Während einige Studien eine inverse Beziehung zwischen Kindheitstrauma und dem Bindungshormon Oxytozin berichteten (z. B. Heim et al. 2009b), fanden andere Studien erhöhte Oxytozinkonzentrationen bei in der Kindheit missbrauchten Personen (z. B. Pierrehumbert et al. 2010; Seltzer et al. 2014). Oxytozin reduziert in der Regel die Stressantwort. So zeigten sich auch in der Studie von Seltzer et al. (2014) die niedrigsten Cortisolwerte als Antwort auf einen psychosozialen Stresstest in der Gruppe der misshandelten Mädchen mit der stärksten Oxytozinausschüttung. Warum Kindesmisshandlung in manchen Fällen mit erhöhten und in anderen mit niedrigeren Oxytozinkonzentrationen einhergeht, ist unklar. Man vermutet, dass die Art und Weise, wie der Betroffene mit dem Trauma umgeht, eine Rolle spielt. So berichteten Mohiyeddini et al. (2014), dass Coping-Strategien, die durch eine Unterdrückung des emotionalen Ausdrucks gekennzeichnet sind (z. B. Gefühle für sich behalten) und möglicherweise mit der Vermeidung sozialer Kontakte in Verbindung stehen, den Zusammenhang zwischen Kindheitstrauma und niedrigen Oxytozinwerten im Erwachsenenalter verstärken.

Kindheitstraumata gehen bei Erwachsenen und Jugendlichen mit erhöhten Entzündungsparametern einher: Erwachsene und Jugendliche, die in ihrer Kindheit misshandelt wurden, wiesen in verschiedenen Studien erhöhte Werte des C-reaktiven Proteins (CRP), höhere Fibrinogenspiegel und proinflammatorische Zytokine auf (Übersicht bei Coelho et al. 2014). Besonders aussagekräftig ist hierbei eine epidemiologische Longitudinalstudie, die einen prospektiven Zusammenhang zwischen Misshandlung in der Kindheit (bis zum 11. Lebensjahr) und erhöhten CRP- bzw. Fibrinogen-Werten sowie einer höheren Anzahl an weißen Blutkörperchen im Alter von 32 Jahren berichtet (Danese et al. 2007). Dieser Zusammenhang war interessanterweise bei Probanden mit einer Depression besonders stark ausgeprägt (Danese et al. 2008). Erhöhte Entzündungswerte spielen möglichweise bei der Vermittlung der Effekte von Kindheitstraumata auf spätere psychische und internistische Erkrankungen eine Rolle.

Wechselwirkungen zwischen traumabedingten Veränderungen in verschiedenen Hormonsystemen: Eine traumabedingte Fehlregulation der HPA-Achse wirkt sich höchstwahrscheinlich auch auf verschiedene andere neuro- 
biologische Systeme aus (z. B. Immunsystem, serotonerge und dopaminerge Systeme), und umgekehrt beeinflussen Fehlregulationen in diesen Systemen wiederum die HPAAchse. Struber et al. (2014) haben ein Modell vorgeschlagen, das anhand hormoneller Wechselwirkungen erklärt, warum Kindheitstraumata sowohl zu einer Hypo- als auch Hyperaktivität der HPA-Achse führen können. Ausschlaggebend ist dabei, ob eine sichere Bindung zu einem Elternteil besteht, was eine vermehrte Oxytozinausschüttung bedingt. Durch die Wechselwirkung des Bindungshormons Oxytozin mit Glukokortikoiden und Serotonin ergibt sich für sicher gebundene traumatisierte Kinder ein anderer biochemischer Entwicklungspfad, der langfristig in einer hyperaktiven HPA-Achse mündet, als für traumatisierte Kinder ohne sichere Bindung (HPA-Achsen-Hypoaktivität; Struber et al. 2014). Hormonelle Wechselwirkungen werden unzureichend verstanden, könnten aber uneinheitliche neurobiologische Befunde in Bezug auf Kindheitstraumata erklären.

Personen, die in ihrer Kindheit misshandelt wurden, weisen im Vergleich zu nicht-misshandelten Personen strukturelle und funktionale Unterschiede im Gehirn auf: Ausgehend von der Hypothese, dass hohe Cortisolkonzentrationen während sensibler Entwicklungsphasen das Gehirn schädigen können, v. a. in Regionen, die eine hohe GR-Dichte aufweisen (z. B. Hippocampus, Amygdala, präfrontaler Kortex; Lupien et al. 2009), untersuchten mehrere Bildgebungsstudien Unterschiede in Gehirnstrukturen und der neuronalen Antwort auf vorgegebene Stimuli zwischen Personen mit und ohne Kindesmisshandlung. In einer aktuellen Übersichtsarbeit über diese Studien gelangen Teicher und Samson (2016) zu dem Ergebnis, dass Kindesmisshandlung mit strukturellen Veränderungen im Corpus callosum, im anterioren zingulären, dorsolateralen präfrontalen und orbitofrontalen Kortex sowie im Hippocampus einhergeht. Während sich ein kleineres Volumen des präfrontalen Kortex sowohl bei misshandelten Kindern als auch Erwachsenen zeigt, ist der Befund eines geringeren hippokampalen Volumens auf Erwachsene beschränkt (Danese und McEwen 2012). Dies könnte bedeuten, dass sich strukturelle Veränderungen des Hippocampus erst mit einer gewissen Latenz oder infolge einer posttraumatischen Belastungsstörung ergeben (PTSD; Smith 2005). Die Ergebnisse funktioneller Bildgebungsstudien ergaben, dass in der Kindheit misshandelte Personen mit einer starken Aktivierung der Amygdala auf negative Stimuli (z. B. ängstliche, ärgerliche Gesichter) sowie einer schwachen Aktivierung von Belohnungsschaltkreisen (Striatum) auf positive Stimuli wie Belohnungsantizipation reagierten (Teicher und Samson 2016).
Mit Kindheitstraumata verbundene neurobiologische Auffälligkeiten als sinnvolle Anpassung an die Umwelt: Ging man früher davon aus, dass die vielfach beobachteten Veränderungen in neurobiologischen Systemen bei in der Kindheit traumatisierten Personen unspezifische Folgen hoher Stresshormonspiegel darstellen (Lupien et al. 2009), nimmt man heute an, dass es sich hierbei um erfahrungsabhängige Adaptationsprozesse an die jeweilige soziale Umwelt handelt (Danese und McEwen 2012; Teicher und Samson 2016). Das stärkere Ansprechen auf Bedrohungsals auf Belohnungsreize lässt z.B. Gefahren schneller erkennen und stellt in einer potenziell gefährlichen Umwelt eine sinnvolle Reaktion dar. Andererseits fördert die verstärkte Wahrnehmung von Gefahren und negativen Reizen die Entwicklung von Depressionen, Ängstlichkeit und Substanzstörungen (Teicher und Samson 2016).

\section{Zusammenfassung neurobiologische Korrelate von Kind-} heitstraumata: Im Mittelpunkt der Forschung zu den neurobiologischen Auswirkungen standen drei eng miteinander verwobene biologische Systeme: endokrines, Immunund Zentralnervensystem. Inzwischen belegen viele Studien, dass Opfer von frühen Traumatisierungen Auffälligkeiten in der Funktionsweise aller drei Systeme aufweisen (Danese und McEwen 2012; McCrory et al. 2011). Wie es zu diesen traumabedingten biologischen Veränderungen kommt, also die genauen biologischen Mechanismen, die diesen Zusammenhängen korrelativer Natur zugrunde liegen, wird dagegen weniger gut verstanden. Genetische Faktoren und durch die Umwelt ausgelöste epigenetische Modifikationen könnten hierbei eine zentrale Rolle spielen (Blaze et al. 2015).

\section{Gene als Moderatoren der Effekte von Kindheitstraumata}

Nicht immer haben Traumata negative Auswirkungen auf den Organismus. Ob jemand nach dem Erleben eines Kindheitstraumas eine psychische Störung entwickelt, scheint u. a. von der genetischen Prädisposition, d.h. von Variationen einzelner Basenpaare im DNA-Strang, abhängig zu sein. Caspi et al. $(2002,2003)$ waren die Ersten, die unter Verwendung molekulargenetischer Methoden nachweisen konnten, dass Genvarianten den viel beobachteten $\mathrm{Zu}$ sammenhang zwischen Kindheitstrauma und psychischen Störungen moderieren. So ließ sich in ihrer ersten wegweisenden Gen-Umwelt-Interaktionsstudie an männlichen Teilnehmern der prospektiven epidemiologischen DunedinStudie nur dann ein Zusammenhang zwischen Kindesmisshandlung und späterem antisozialem Verhalten nachweisen, wenn die Betroffenen Träger der niedrig-aktiven Variante des Monoaminoxidase-A-Gen (MAOA-L) waren (Tab. 1). 


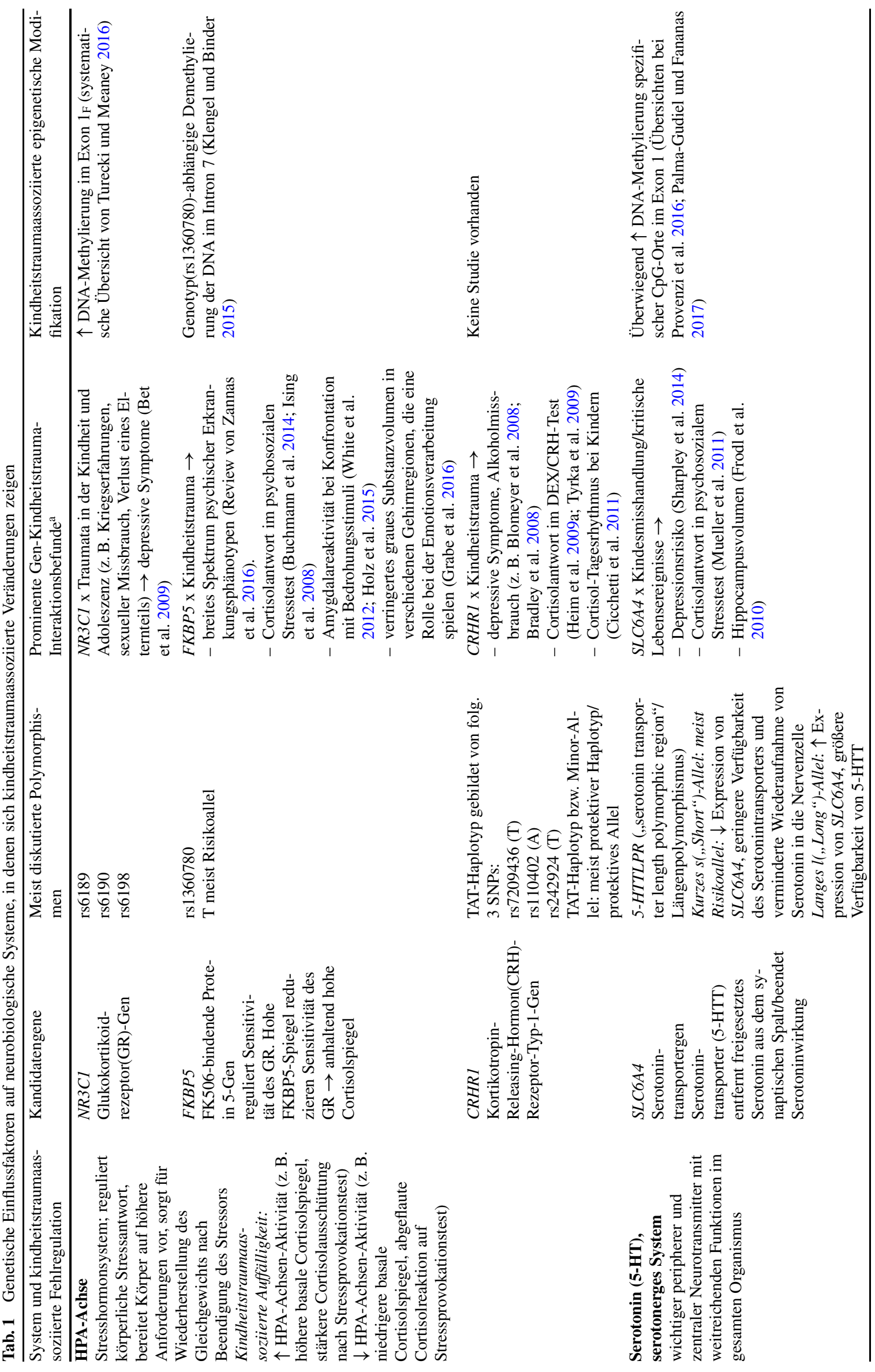




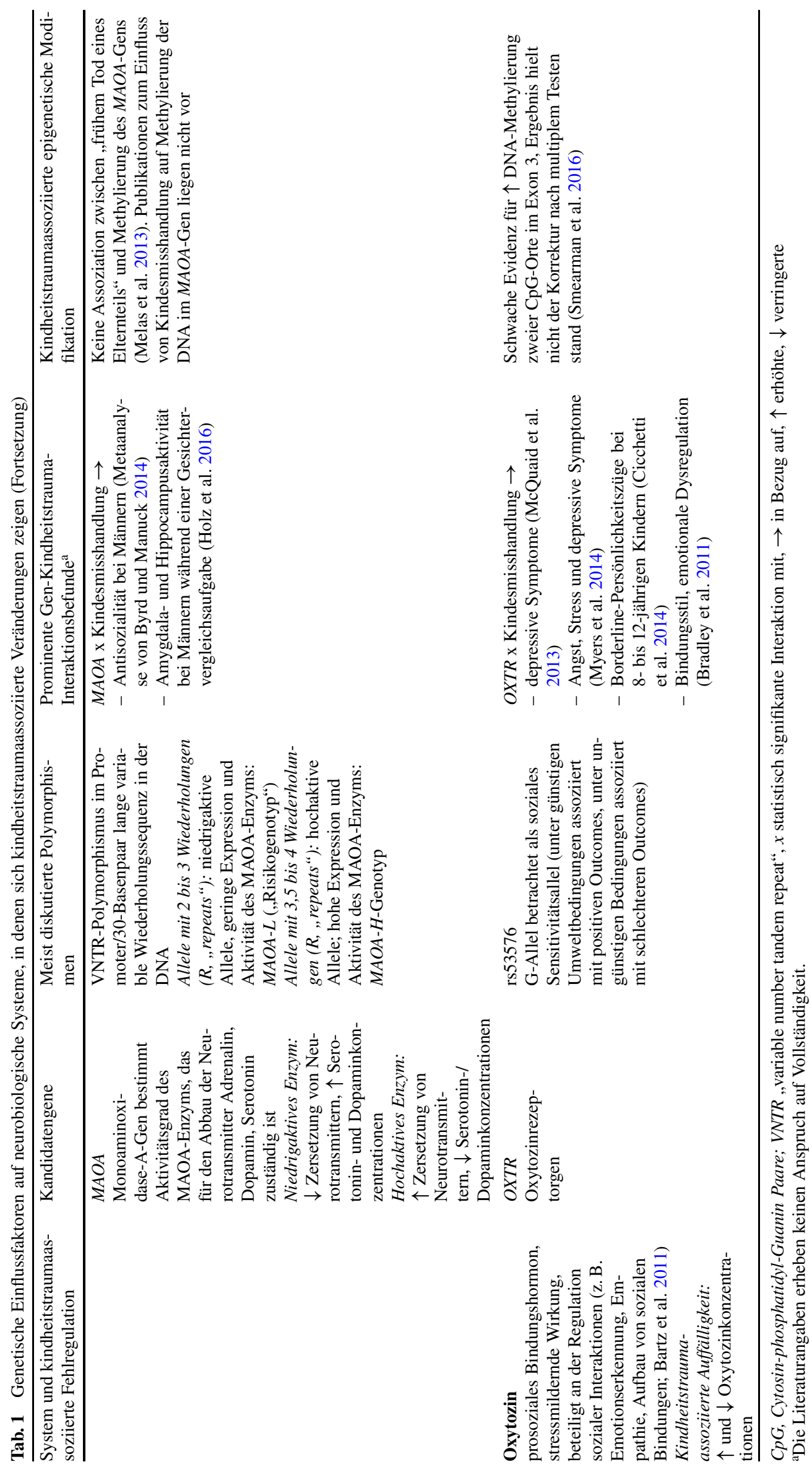


Misshandelte Jungen mit dem Risikogenotyp (MAOA-L) entwickelten im Vergleich zu nichtmisshandelten Jungen mit dem gleichen Genotyp signifikant häufiger Verhaltensstörungen, eine höhere Gewaltneigung, mehr Merkmale einer antisozialen Persönlichkeitsstörung und wurden häufiger wegen eines Gewaltdelikts strafrechtlich verurteilt (Caspi et al. 2002). Die neueste Metaanalyse zu dem Thema, die die Effekte von 27 nichtklinischen Studien mit etwas mehr als 18.400 Studienteilnehmern zusammenfasst, gelangte ebenfalls zu dem Ergebnis, dass die Entwicklung antisozialen Verhaltens infolge von Kindesmisshandlung bei Männern vom MAOA-Genotyp abhängt (Byrd und Manuck 2014).

In ihrer viel beachteten Folgestudie berichteten Caspi et al. (2003) eine signifikante Gen-Umwelt-Interaktion (GxE) zwischen dem Längenpolymorphismus (5-HTTLPR) im Serotonintransporter(5-HTT)-Gen (SLC6A4) und Kindesmisshandlung sowie kritischen Lebensereignissen hinsichtlich der Vorhersage depressiver Erkrankungen. Bei Vorliegen von Kindesmisshandlung wiesen homozygote Träger des kürzeren Allels das höchste Depressionsrisiko auf, gefolgt von Heterozygoten mit nur einer Kopie des kurzen Allels. Anders als bei MAOA, sind die Ergebnisse verschiedener Metaanalysen zur 5-HTTLPR-GxE nicht konsistent. Dies könnte daran liegen, dass nicht immer zwischen verschiedenen Typen von Umweltfaktoren differenziert wurde. In zwei neueren Metaanalysen zeigte sich ein signifikanter 5-HTTLPR-Interaktionseffekt z.B. nur für Kindesmisshandlung und medizinische Faktoren (z. B. schwere Erkrankung), aber nicht für kritische Lebensereignisse (Karg et al. 2011; Sharpley et al. 2014). Die Ergebnisse einer groß angelegten kollaborativen Metaanalyse, die zwischen verschiedenen Stressoren differenziert und unveröffentlichte Daten einbezieht, stehen noch aus (Culverhouse et al. 2013).

Auf die Studien von Caspi et al. (2002, 2003) folgten zahlreiche GxE-Studien, die die initialen Befunde zur Moderatorrolle genetischer Polymorphismen auf andere Phänotypen und Gene ausdehnten. Auf die Gesamtheit dieser Studie kann aus Platzgründen nicht eingegangen werden. In eigenen Arbeiten konzentrierten wir uns auf das FK506bindende Protein 5 Gen (FKBP5), ein HPA-Achsen-Gen, das die Sensitivität des GR reguliert.

FKBP5: FKBP5 codiert für ein Kochaperon (Helferprotein) des Hitzeschockprotein 90 (hsp90), das die Bindungsfähigkeit des GR an Cortisol im Zellkern hemmt. Die Expression von FKBP5 wird wiederum durch die Anbindung des GR an GRE der DNA induziert, was einer ultrakurzen negativen Feedback-Schleife gleichkommt: GR induziert FKBP5, welches daraufhin die GR-Aktivität vermindert. Wie stark FKBP5 bei Aktivierung des GR exprimiert wird, hängt wiederum von Polymorphismen im FKBP5-
Gen ab. Träger des Risikoallels ( $\mathrm{T}$ am SNP rs1360780) weisen eine stärkere FKBP5-Expression aus. Hohe FKBP5Spiegel können die negative Feedback-Schleife der HPAAchse empfindlich stören: Glukokortikoide können weniger gut an den GR binden, die Beendigung der Stressantwort durch Aktivierung des GR-Rezeptors bleibt aus, und es kommt zu einer anhaltenden Stressreaktion bzw. Cortisolsekretion (Binder 2009; Halldorsdottir und Binder 2017).

Wir konnten u. a. zeigen, dass sich sowohl der Schweregrad aktueller PTSD-Symptome (Binder et al. 2008) als auch ein erhöhtes prospektives Depressionsrisiko durch eine signifikante Interaktion zwischen FKBP5 und Kindheitstraumata vorhersagen lässt (Zimmermann et al. 2011). Andere Arbeitsgruppen konnten unsere initialen Befunde zur FKBP5GxE bestätigen und um andere auch sog. intermediäre Phänotypen erweitern (Zannas et al. 2016; Zannas und Binder 2014). Von Letzteren wird angenommen, dass sie zeitlich zwischen Traumaexposition und Krankheitsausbruch und somit näher am vermuteten ursächlichen Mechanismus liegen als manifeste Erkrankungen (z. B. strukturelle und funktionale Auffälligkeiten im Gehirn, Stressreaktion, etc.). Mittlerweile konnten GxE von FKBP5 mit einem frühen Trauma in Studien mit über 20.000 Teilnehmern bestätigt werden. Tab. 1 fasst einige der wichtigsten GxE-Befunde in Bezug auf Kindheitstraumata kurz zusammen und geht insbesondere auf Gene ein, für die mittlerweile erste epigenetische Untersuchungen vorliegen.

Zusammenfassung GxE-Studien: Trotz der berechtigten Kritik an GxE-Studien (z. B. die Gefahr eines hohen Anteils falsch-positiver Ergebnisse durch unterpowerte Analysen, bevorzugte Publikation von positiven signifikanten Resultaten, unsachgemäße Verwendung von Kovariaten; z. B. Duncan und Keller 2011; Keller 2014), wäre es falsch anzunehmen, dass GxE per se nicht existieren. GxE stellen nach wie vor ein plausibles Erklärungsmodell für individuelle Auswirkungen von Kindheitstraumata dar (Rutter et al. 2006). Zu den aus GxE-Studien gewonnenen Erkenntnissen zählen unter anderem:

- GxE haben in der Regel ein breites Wirkspektrum. Die gleichen Risikoallele wurden bei Vorliegen von Kindheitstraumata mit verschiedenen psychischen Erkrankungen in Verbindung gebracht.

- Die meisten GxE-Studien finden keine genetischen Haupteffekte. Dies impliziert, dass sich die Wirkung bestimmter Gene erst bei Konfrontation mit einem bestimmten Umweltfaktor entfaltet. Ist das Individuum dem Umweltrisiko (z. B. Kindheitstrauma) nicht ausgesetzt, treten die ungünstigen Effekte eines bestimmten Genotyps nicht in Erscheinung. 
- Der Zusammenhang zwischen einem sog. Risikoallel und ungünstigen gesundheitlichen Folgen ist nicht immer eindeutig. Träger des „Risikoallels“ hatten in den Gruppen ohne Kindheitstrauma oft niedrigere Psychopathologiewerte als Träger des ,protektiven Allels“ („Crossover"-Interaktionen; z. B. Binder et al. 2008). Dies legt nahe, dass sich die Wirkung eines Allels unter günstigen Umweltbedingungen umkehren kann. Belsky und Pluess (2013) argumentieren deshalb, dass es sich bei den sog. Risikoallelen um Plastizitätsallele handelt, die generell mit einer erhöhten Empfänglichkeit für Umwelteffekte, positive wie negative, einhergehen.

- Nicht ein SNP oder Gen allein, sondern zahlreiche Genvarianten scheinen die Auswirkungen von Kindheitstraumata zu moderieren. Genomweite GxE-Studien, die für den Bereich Kindheitstrauma noch fehlen, könnten zur Aufdeckung bislang unbekannter genetischer Einflussfaktoren beitragen.

- Inwieweit eine hohe genetische Disposition für eine bestimmte Erkrankung den Einfluss eines Kindheitstraumas auf die Entstehung derselben Erkrankung verstärkt (Peyrot et al. 2014) oder aber schwere Kindesmisshandlung einen so starken Risikofaktor darstellt, der unabhängig vom genetischen Risiko Depressionen auslöst (Mullins et al. 2016), muss in weiteren polygenen GxE-Studien geklärt werden.

Die Validierung eines GxE-Befunds über verschiedene Analyseebenen (Abb. 1) unter Einbezug molekularer und zellulärer Prozesse ist ein vielversprechender Ansatz, um methodische Artefakte von wahren GxE zu trennen (Halldorsdottir und Binder 2017).

\section{Mechanismen}

\section{Epigenetik}

Man nimmt an, dass Änderungen im Epigenom (dazu gehören DNA-Methylierung, Hydroxymethylierung, Histonmodifikation, nichtcodierende RNA, ATP-abhängige Chromatinveränderung) einen zentralen Mechanismus darstellen, über den GxE und lang anhaltende Einflüsse von Kindheitstraumata (Abb. 1) biologisch vermittelt werden (Blaze et al. 2015). Epigenetische Modifikationen führen zu Veränderungen in der Genexpression/-aktivität, d.h., sie bestimmen, ob und in welchem Ausmaß ein Gen exprimiert (eingeschaltet), abgelesen (Transkription) und in Proteine übersetzt (Translation) wird. Eine bestimme Genvariante kann nur dann ihre Wirkung entfalten, wenn das Gen exprimiert wird.

Eine Schwierigkeit epigenetischer Forschung am Menschen besteht darin, dass epigenetische Marker gewebespe- zifisch sind, d.h., das Methylierungsmuster ein und desselben Gens unterscheidet sich in Gehirnzellen und peripheren Zellen voneinander. Mittlerweile liegen erste Hinweise vor, dass sich leicht zu gewinnende periphere Zellen zur Untersuchung epigenetischer Folgen von Umwelteinflüssen eignen. Provençal et al. (2012) konnten z. B. zeigen, dass Rhesusaffen, die getrennt von ihrer Mutter aufwuchsen, nicht nur im präfrontalen Kortex, sondern auch in peripheren T-Zellen Veränderungen in der DNA-Methylierung aufwiesen.

\section{Methylierung einzelner Gene in Abhängigkeit von Kindheitstraumata}

Glukokortikoid-Rezeptorgen (NR3C1): Den Beginn für die Untersuchung epigenetischer Reaktionen auf frühe Umwelterfahrungen markiert eine Arbeit von Weaver et al. (2004) an Ratten. Die Autoren konnten erstmals zeigen, dass frühe soziale Erfahrungen epigenetische Veränderungen nach sich ziehen, die sich bis ins Erwachsenenalter auf die Stressreaktivität der Tiere auswirken. So wiesen Ratten, die in der ersten Woche nach der Geburt viel mütterliche Fürsorge (in Form von Lecken und Fellpflege) erfuhren, im Vergleich zu wenig umsorgten Ratten, eine geringere DNAMethylierung im Promotor des GR-Gens ( $\mathrm{Nr} 3 \mathrm{cl}$ ) und eine erhöhte Expression des GR im Hippocampus auf (Weaver et al. 2004). In früheren Experimenten zeigten die gut umsorgten Ratten neben einer höheren hippokampalen GR-Expression eine moderatere Cortisol- und ACTH-Antwort auf Stress (Liu et al. 1997). McGowan et al. (2009) konnten diese Befunde nahezu eins zu eins auf den Menschen übertragen und erbrachten damit den ersten Nachweis für einen $\mathrm{Zu}$ sammenhang von Kindesmisshandlung mit epigenetischen Markern beim Menschen. In ihrer Post-Mortem-Studie an jeweils 12 Suizidopfern mit und ohne schweren Missbrauch in der Kindheit und 12 Kontrollen, die einen plötzlichen Tod erlitten, zeigten sich nur bei Suizidopfern, die in ihrer Kindheit missbraucht wurden, eine höhere DNA-Methylierung im Promotor von $\mathrm{NR} 3 \mathrm{Cl}$ sowie eine verminderte Expression von GR im Hippocampus. Die deutliche Mehrheit der nachfolgenden Humanstudien konnten den Befund einer erhöhten DNA-Methylierung infolge von Kindesmisshandlung und anderen Kindheitstraumata bestätigen, obwohl sie mehrheitlich den Methylierungsstatus des GR in peripheren Blutzellen und nicht wie die ursprüngliche Studie in Gehirnproben untersuchten (Turecki und Meaney 2016). Weitere Studien erbrachten zwischenzeitlich außerdem den Nachweis, dass eine erhöhte NR3C1-Methylierung mit verschiedenen psychopathologischen Symptomen zusammenhängt (z. B. Radtke et al. 2015).

FKBP5: In eigenen Arbeiten ist es uns gelungen, erstmalig den molekulargenetischen Mechanismus einer GxE 
aufzuklären. Anhand von Daten aus dem Grady-TraumaProjekt, das mehrheitlich von Armut betroffene und mehrfach traumatisierte Afroamerikaner umfasst, konnten wir nachweisen, dass die FKBP5-GxE bezüglich PTSD über eine allelspezifische DNA-Methylierung in einem funktionalen GRE von FKBP5 vermittelt wird (Klengel und Binder 2015; Klengel et al. 2013). Probanden, die in ihrer Kindheit sexuell und physisch missbraucht wurden, wiesen im Vergleich zu nichtmissbrauchten Probanden eine geringere Methylierung der DNA in einem GRE im Intron 7 des FKBP5Gens auf, allerdings nur, wenn sie Träger des T-Allels am SNP rs1360780 waren. Dass die Demethylierung dieses Locus für die Transkription und Expression von FKBP5 von Relevanz ist, konnte in einer Reihe von Zellexperimenten nachgewiesen werden (Klengel et al. 2013). Für Traumatisierungen im Erwachsenenalter ließ sich keine Demethylierung des FKBP5-Gens nachweisen. Die epigenetischen Veränderungen könnten auf sensible Perioden in der Kindheit beschränkt sein. Im Einklang damit sind die Ergebnisse einer direkt an Kindern durchgeführten Studie, die eine signifikante Demethylierung der DNA an der gleichen Stelle des FKBP5 Gens bei 3- bis 5-Jährigen mit einer durch die Kinderfürsorge dokumentierten Misshandlung beobachtete (Tyrka et al. 2015). Wir vermuten, dass Kindheitstraumata und damit verbundene hohe Stresshormonkonzentrationen bei Individuen mit einer genetischen Vorbelastung (T-Allel am SNP rs1360780) eine Demethylierung im FKBP5-Gen auslöst, wodurch die bereits genetisch bedingte hohe Aktivität von FKBP5 zusätzlich gesteigert wird. Hohe FKBP5Spiegel wiederum beeinträchtigen den über den GR vermittelten negativen Feedback-Mechanismus, und es kommt zu einer anhaltenden Aktivierung der HPA-Achse (Klengel und Binder 2015; Klengel et al. 2013).

Serotonintransportergen (SLC6A4): Beach et al. (2010, 2011) waren die Ersten, die - anhand von Daten aus der Iowa-Adoptionsstudie - eine erhöhte Methylierung im Promotor von SLC6A4 bei in der Kindheit physisch und sexuell missbrauchten Erwachsenen und insbesondere bei sexuell missbrauchten Frauen berichteten. Weiterführende Analysen ergaben, dass die mit sexuellem Missbrauch assoziierte stärkere SLC6A4-Methylierung mit Symptomen einer antisozialen Persönlichkeitsstörung korrelierte, insbesondere bei Trägerinnen des S-Allels (Beach et al. 2013, 2011). Die einzige Longitudinalstudie auf diesem Gebiet ergab, dass eineiige Zwillinge, die massivem Mobbing durch Gleichaltrige ausgesetzt waren, im Alter von 10 Jahren nicht nur eine stärkere Methylierung von SLC6A4 aufwiesen als die Zwillinge ohne Mobbing-Erfahrung, sondern auch eine gedämpfte Cortisolreaktion auf einen psychosozialen Stresstest im Alter von 12 Jahren (Ouellet-Morin et al. 2013). Der genaue Mechanismus, der diesen Befunden zugrunde liegt, konnte bislang jedoch noch nicht aufgeklärt werden. In der Adoptionsstichprobe aus Iowa ließ sich zwar insgesamt ein Zusammenhang zwischen der Methylierung bestimmter Stellen des Serotonintransportergens und der Genexpression nachweisen, aber nicht speziell für die Region, deren Methylierungsstatus sich durch das Kindheitstrauma und den Genotyp vorhersagen ließ (Vijayendran et al. 2012).

\section{Epigenomweite Studien}

Eine rasch wachsende Anzahl von Studien befasst sich mit der Frage, ob Kindheitstraumata einen weitreichenderen Einfluss haben als nur auf einzelne Kandidatengene. In der ersten epigenomweiten Studie entdeckten Labonte et al. (2012) 362 unterschiedlich methylierte Promotoren im Hippocampus von männlichen Suizidopfern, die in ihrer Kindheit schwer missbraucht wurden, im Vergleich zu Kontrollen, die aus Suizidopfern und plötzlich Verstorbenen ohne Missbrauchserfahrung bestanden. Die größten Methylierungsunterschiede zeigten sich für Gene, die in die neuronale Plastizität involviert sind. Nachfolgende Studien mit peripheren epigenetischen Markern ermittelten eine z. T. noch höhere Anzahl unterschiedlich methylierter Gene bei Personen, die Kindheitstraumata oder anderen widrigen Kindheitsumständen ausgesetzt waren. Die Unterschiede betrafen in erster Linie Gene, die eine Rolle bei der Erregungsübertragung zwischen Nervenzellen oder der Transkription von DNA in mRNA spielen (z. B. Mehta et al. 2013; Suderman et al. 2014).

Zusammenfassung Epigenetik: Im Fokus bisheriger Humanstudien zu den epigenetischen Auswirkungen früher Traumatisierungen standen Unterschiede in der DNA-Methylierung einiger weniger Kandidatengene (v. a. $N R 3 C 1$, SLC6A4) in peripheren Zellen. Andere Gene und epigenetische Mechanismen sind beim Menschen im Zusammenhang mit Kindheitstraumata weitestgehend unerforscht. Fast für jedes der untersuchten Kandidatengene zeigte sich ein Zusammenhang mit einer veränderten Methylierung bei in der Kindheit traumatisierten Personen, auch wenn, wie im Fall von SLC6A4, Ergebnisrichtung (Hypo- vs. Hypermethylierung) und Methylierungsort nicht immer übereinstimmten. Was den genauen Mechanismus betrifft, nehmen wir an, dass frühe Traumata Transkriptionsprozesse in der Zelle verändern: Durch die Anbindung einer Methylgruppe an ein CpG-Dinukleotid verändern sich die Chromatinstruktur (3-dimensionale Struktur) der DNA und damit die Zugänglichkeit dieser DNA-Stellen für Transkriptionsregulatoren. Darüber hinaus scheinen bestimmte Risikoallelle epigenetische Modifikationen zu begünstigen. Das Risikoallel des FKBP5-SNP rs1360780 (T-Allel) geht z.B. mit einer anderen Chromatinformation einher, die einen direkten Kontakt des GRE im Intron 2 mit der Transkriptions-Start-Seite (TSS) begünstigt und so zu einer 
erhöhten FKBP5-Expression führt (Zannas et al. 2016). Genomweite Studien legen zudem nahe, dass Traumatisierungen in der Kindheit Spuren in der DNA zahlreicher Gene hinterlassen.

\section{Telomere}

Als Telomere bezeichnet man die lange Wiederholungssequenz der Nukleotide TTAGGG an Chromosomenenden, die die DNA bei der Replikation vor dem Zerfall schützt (Price et al. 2013). Telomere verkürzen sich mit jeder Zellteilung, und die Länge der Telomere gilt als Indikator für biologisches Altern. Genau wie epigenetische Marker ist die Telomerlänge gewebespezifisch und unterscheidet sich zwischen unterschiedlichen Zelltypen (Blaze et al. 2015). Erste Studien mit z. T. kleinem Stichprobenumfang deuten an, dass bestimmte aversive Kindheitserfahrungen wie Vernachlässigung, physische Misshandlung sowie Indikatoren mangelnder elterlicher Feinfühligkeit mit einer kürzeren Telomerlänge assoziiert sind (zusammengefasst in Blaze et al. 2015; Price et al. 2013). Eine dieser Studien verdient besondere Erwähnung, da sie aufgrund der prospektiven Messung sowohl der Telomerlänge als auch der Gewalterfahrungen eine Erosion der Telomerlänge bei 5- bis 10-jährigen Kindern infolge von multiplen Gewaltexpositionen im häuslichen Umfeld demonstrierte (Shalev et al. 2013). In der Summe deuten diese vorläufigen Befunde einen beschleunigten Alterungsprozess infolge von widrigen Kindheitsumständen an.

\section{Auswirkung von traumaassoziierten neurobiologischen Veränderungen auf psychische Funktionen und Erkrankungen}

In einigen Studien konnten die mit Kindheitstraumata verbundenen Methylierungsunterschiede direkt mit Auffälligkeiten in der Stressregulation oder Symptomen psychischer Erkrankungen in Verbindung gebracht werden (z. B. Beach et al. 2011; Klengel et al. 2013; Yehuda et al. 2016). Abgesehen davon ist es bislang aber nur wenigen Studien gelungen, die Ergebnisse zu den Auswirkungen von Kindheitstraumata über mehrere Analyseebenen zu integrieren (Abb. 1). Obwohl bekannt ist, dass Kindheitstraumata mit verschiedenen neurobiologischen Auffälligkeiten einhergehen, ist bislang unklar, zu welchem Grad diese direkt für Veränderungen in Verhalten, emotionalem Erleben und Erkrankungsrisiko verantwortlich sind. Dies ist auch für die forensische Praxis eine wichtige Frage. So wurde z. B. der MAOA-Befund von Caspi et al. (2002) im Jahr 2009 erstmalig vor einem europäischen Gericht verwendet, um die Strafe eines überführten Mörders um ein Jahr zu kürzen (der Bayout-Fall, Feresin 2009). Das komplexe Wechselspiel zwischen traumainduzierter Fehlregulation in neurobiologischen und psychischen Funktionen über lange Zeiträume hinweg erschwert die Entschlüsselung kausaler Prozesse. Stellt eine gedämpfte Cortisolreaktion auf akuten Stress, die wiederholt bei traumatisierten Kindern beobachtet wurde, z. B. einen Risikofaktor für Verhaltensprobleme und die Entwicklung externalisierender Störungen dar, wie einige Studien nahelegen (z. B. Jaffee et al. 2015; Ouellet-Morin et al. 2011)? Oder sind die bei misshandelten Kindern beobachteten Probleme im Sozialverhalten eher ein Prädiktor für geringe basale Cortisolwerte (Alink et al. 2012). Je weiter die betrachteten Auswirkungen zeitlich und systemisch von unmittelbaren neurobiologischen Folgen (Ebene 1 in Abb. 1) entfernt liegen, desto mehr Faktoren kommen als zusätzlich moderierende Einflüsse infrage. Das hypothetische Fallbeispiel unten soll veranschaulichen, wie wir uns die komplexen Auswirkungen früher Traumatisierungen in Abhängigkeit von genetischen Faktoren (am Beispiel von FKBP5) vorstellen.

Hypothetisches Fallbeispiel: Ben ist 6 Jahre alt und wird seit seinem 3. Lebensjahr von seinen Eltern physisch misshandelt. Durch die ständige Missbrauchserfahrung und die tägliche Bedrohung sind seine Stresshormonwerte erhöht. Aufgrund einer genetischen Vorbelastung (T-Allel am FKBP5-SNP rs1360780) ist bei Ben der FeedbackMechanismus zur Herunterregulierung der Stresshormonachse beeinträchtigt. Auf jede Form von Stress reagiert er mit einer verlängerten Cortisolausschüttung. Die wiederholten Misshandlungen führen bei ihm in Verbindung mit der genetischen Vorbelastung zu einem Cortisolüberschuss, der sich auf den gesamten Organismus auswirkt. Auf der Zellebene löst er eine Demethylierung im FKBP5Gen aus. Die Folgen dieser epigenetischen Modifikation sind eine noch stärkere Induktion von FKBP5 und somit eine noch stärkere Aktivierung der Stresshormonachse bei erneutem Stress. Die erfahrene Misshandlung beeinflusst auch, wie Ben mit Gleichaltrigen umgeht. Er fühlt sich schneller angegriffen, reagiert stärker auf Bedrohungs-/ Ablehnungssignale (erhöhte Amygdalareaktivität) und ist seinen Mitschülern gegenüber aggressiv. Die damit verbundenen sozialen Probleme (stärkere Ablehnung durch Mitschüler) erzeugen zusätzlichen Stress, der wiederum die HPA-Achse aktiviert. Ben hat Schwierigkeiten, sich in der Schule zu konzentrieren. Er entwickelt zunehmend Symptome einer Verhaltensstörung.

\section{Weitergabe von Traumata an die nächste Generation}

Mittlerweile liegen nicht nur aus dem Tiermodell Hinweise vor, dass bereits vorgeburtliche Traumatisierungen der 
Eltern beim Nachwuchs epigenetische Modifikationen hinterlassen können, ohne dass der Nachwuchs selbst traumatisiert wurde (Blaze et al. 2015; Provençal und Binder 2015). Dies konnte insbesondere für Belastungen der Mutter während der Schwangerschaft nachgewiesen werden. Eine erhöhte DNA-Methylierung des GR-Gens zeigte sich beispielsweise bei Kindern von Müttern, die während der Schwangerschaft körperlicher Gewalt durch den Partner ausgesetzt waren (Radtke et al. 2011). Im Sinne einer fetalen Programmierungshypothese werden diese Ergebnisse u. a. durch den direkten Kontakt des Fetus mit erhöhten Glukokortikoidkonzentrationen der Mutter erklärt (z. B. Harris und Seckl 2011). Aber auch frühe Traumata der Mütter scheinen sich auf den Verlauf der Schwangerschaft auszuwirken. So wurden bei in der Kindheit traumatisierten Frauen ein erhöhtes Risiko für verschiedene Schwangerschaftsund Geburtskomplikationen (Leeners et al. 2010) sowie erhöhte plazentale CRH-Werte festgestellt (Moog et al. 2016), die evtl. bereits im Mutterleib epigenetische Veränderungen beim Nachwuchs auslösen könnten.

$\mathrm{Ob}$ traumassoziierte epigenetische Marker beim Menschen auf die nachfolgende Generation (über die Keimzelle) vererbt werden, ist jedoch unklar. In einer Studie an Holocaustopfern und ihren Kindern, die nach 1945 zur Welt kamen, beobachteten wir zwar in beiden Generationen Holocausttrauma-abhängige Unterschiede in der Methylierung einer speziellen Stelle des FKBP5-Gens im Vergleich zu einer jeweils gleichaltrigen Kontrollgruppe, aber die Richtung der Effekte stimmte nicht überein. Während die Elterngeneration eine Hypermethylierung aufwies, zeigte sich bei den Kindern eine Hypomethylierung der DNA (Yehuda et al. 2016). Verschiedene In-utero- und postnatale Effekte kommen als Erklärung für die beobachteten Transmissionseffekte infrage. Eine direkte Vererbung der epigenetischen Modifikationen über die Keimzelle legen die Daten jedoch nicht nahe.

\section{Abschließende Betrachtung und methodische Aspekte}

Kindheitstraumata gehen mit Auffälligkeiten in der hormonellen Stressantwort, Immunreaktion, neuronalen Entwicklung und Gehirnstruktur einher (Danese und McEwen 2012). Man vermutet, dass diese traumabedingten Veränderungen in grundlegenden biologischen Systemen zur erhöhten Vulnerabilität für psychische und andere Erkrankungen beitragen, die man häufig bei Opfern von Kindesmisshandlung findet. Eine rasch steigende Zahl epigenetischer Studien legt nahe, dass diese lang anhaltenden Effekte zumindest teilweise über epigenetische Modifikationen vermittelt werden, die in Transkriptionsprozesse in der Zelle eingreifen.
In der Summe demonstrieren die epigenetischen Humanstudien, dass sich auch im peripheren Gewebe Zusammenhänge zwischen Kindheitstrauma und spezifischen Methylierungsmustern nachweisen lassen. Dies legt die Vermutung nahe, dass traumabedingte epigenetische Veränderungen systemweit erfolgen (evtl. durch nachgeschaltete komplexe Prozesse) und nicht allein auf das zentrale Nervensystem beschränkt sind. Die mit Kindheitstrauma assoziierten peripheren epigenetischen Marker könnten somit zentrale Prozesse nicht nur abbilden, sondern selbst für gesundheitliche Risiken oder Verhaltensauffälligkeiten verantwortlich sein (Pape und Binder 2014). Letzteres gilt auch für traumainduzierte Veränderungen in anderen neurobiologischen Systemen und psychischen Funktionsbereichen. Durch das Trauma hervorgerufene hohe Stresshormonpegel oder bekannte Sekundärfolgen von Kindheitstraumata (z. B. soziale Verhaltensprobleme, psychische Erkrankungen) können eigenständig und unabhängig vom Trauma biologische Veränderungen bewirken. Eine Schwierigkeit besteht also in der Trennung der primären Effekte des Traumas von den nachgeschalteten Sekundäreffekten der Traumafolgen.

Traumatisierte Kinder sind zudem meistens mehreren Traumata und ungünstigen familiären Bedingungen gleichzeitig ausgesetzt (Dong et al. 2004). Dies erschwert die Untersuchung spezifischer Traumaeffekte. Welches Trauma zu welchem Zeitpunkt (bzw. in welcher Entwicklungsphase) welche neurobiologischen Folgen nach sich zieht, wird bislang ungenügend verstanden.

Die meisten epigenetischen Befunde stammen aus retrospektiven Querschnittstudien an Erwachsenen, die keine Aussagen über die Reihenfolge der Effekte zulassen. Man weiß also nicht sicher, ob die beobachteten Unterschiede in der DNA-Methylierung nicht schon vor der Traumatisierung bestanden. Bislang liegt nur eine Longitudinalstudie vor (Ouellet-Morin et al. 2013), die sicherstellen konnte, dass die traumaassoziierte epigenetische Modifikation zeitlich nach der Traumaexposition auftrat und somit tatsächlich als Reaktion auf das Trauma betrachtet werden kann.

Ungeklärt ist auch, inwieweit epigenetische Modifikationen reversibel sind. Weaver et al. (2005) konnten im Tiermodell zeigen, dass sich die durch mütterliches Verhalten induzierten Methylierungsveränderungen im GR und in der Stressreaktivität der Tiere durch die Injektion von Substanzen, die in den Methylierungsprozess eingreifen, rückgängig machen lassen. Erste Ergebnisse einer Humanstudie deuten an, dass sich die Effekte von postnataler mütterlicher Depression auf eine erhöhte Methylierung des GR beim Kind durch vermehrtes mütterliches Streicheln des Babys in den ersten 5 Lebenswochen reduzieren lassen (Murgatroyd et al. 2015). Sollte sich die Reversibilität epigenetischer Veränderungen in künftigen Studien bestätigen, würde dies neue Wege und Ansatzpunkte für die Prävention eröffnen. Lassen sich traumainduzierte epigenetische Veränderungen 
und damit verbundene Auswirkungen auf die Gesundheit durch die rechtzeitige Gabe speziell dafür entwickelter Medikamente oder durch eine frühe psychotherapeutische Intervention rückgängig machen, bevor sie Gesundheitsschäden nach sich ziehen? Solche Fragen lassen anstelle von Erkrankungen unmittelbare biologische Folgen von Traumata in den Mittelpunkt der Behandlung treten. Eine Aufklärung der molekularen Mechanismen, mithilfe derer die Effekte von Traumata auf die Gesundheit vermittelt werden, wird die Entwicklung vielversprechender Therapien fördern, die an den Ursachen und nicht den Folgen ansetzen.

Open access funding provided by Max Planck Society.

Open Access Dieser Artikel wird unter der Creative Commons Namensnennung 4.0 International Lizenz (http://creativecommons.org/ licenses/by/4.0/deed.de) veröffentlicht, welche die Nutzung, Vervielfältigung, Bearbeitung, Verbreitung und Wiedergabe in jeglichem Medium und Format erlaubt, sofern Sie den/die ursprünglichen Autor(en) und die Quelle ordnungsgemäß nennen, einen Link zur Creative Commons Lizenz beifügen und angeben, ob Änderungen vorgenommen wurden.

\section{Literatur}

Albers EM, Riksen-Walraven JM, Sweep FC, de Weerth C (2008) Maternal behavior predicts infant cortisol recovery from a mild everyday stressor. J Child Psychol Psychiatry 49(1):97-103

Alink LR, Cicchetti D, Kim J, Rogosch FA (2012) Longitudinal associations among child maltreatment, social functioning, and cortisol regulation. Dev Psychol 48(1):224-236

Bartz JA, Zaki J, Bolger N, Ochsner KN (2011) Social effects of oxytocin in humans: Context and person matter. Trends Cogn Sci 15(7):301-309

Beach SR, Brody GH, Todorov AA, Gunter TD, Philibert RA (2010) Methylation at SLC6A4 is linked to family history of child abuse: An examination of the Iowa adoptee sample. Am J Med Genet B Neuropsychiatr Genet 153B(2):710-713

Beach SR, Brody GH, Todorov AA, Gunter TD, Philibert RA (2011) Methylation at 5HTT mediates the impact of child sex abuse on women's antisocial behavior: an examination of the Iowa adoptee sample. Psychosom Med 73(1):83-87

Beach SR, Brody GH, Lei MK, Gibbons FX, Gerrard M, Simons RL, Cutrona CE, Philibert RA (2013) Impact of child sex abuse on adult psychopathology: a genetically and epigenetically informed investigation. J Fam Psychol 27(1):3-11

De Bellis MD, Chrousos GP, Dorn LD, Burke L, Helmers K, Kling MA, Trickett PK, Putnam FW (1994) Hypothalamic-pituitary-adrenal axis dysregulation in sexually abused girls. J Clin Endocrinol Metab 78(2):249-255

Belsky J, Pluess M (2013) Beyond risk, resilience, and dysregulation: phenotypic plasticity and human development. Dev Psychopathol 25(4 Pt 2):1243-1261

Bet PM, Penninx BW, Bochdanovits Z, Uitterlinden AG, Beekman AT, van Schoor NM, Deeg DJ, Hoogendijk WJ (2009) Glucocorticoid receptor gene polymorphisms and childhood adversity are associated with depression: New evidence for a gene-environment interaction. Am J Med Genet B Neuropsychiatr Genet $150 \mathrm{~B}(5): 660-669$

Binder EB (2009) The role of FKBP5, a co-chaperone of the glucocorticoid receptor in the pathogenesis and therapy of affective and anxiety disorders. Psychoneuroendocrinology 34(Suppl 1):S186-S195
Binder EB, Bradley RG, Liu W, Epstein MP, Deveau TC, Mercer KB, Tang Y, Gillespie CF, Heim CM, Nemeroff CB, Schwartz AC, Cubells JF, Ressler KJ (2008) Association of FKBP5 polymorphisms and childhood abuse with risk of posttraumatic stress disorder symptoms in adults. JAMA 299(11):1291-1305

Blaze J, Asok A, Roth TL (2015) The long-term impact of adverse caregiving environments on epigenetic modifications and telomeres. Front Behav Neurosci 9:79

Blomeyer D, Treutlein J, Esser G, Schmidt MH, Schumann G, Laucht M (2008) Interaction between CRHR1 gene and stressful life events predicts adolescent heavy alcohol use. Biol Psychiatry 63(2):146-151

Bradley B, Westen D, Mercer KB, Binder EB, Jovanovic T, Crain D, Wingo A, Heim C (2011) Association between childhood maltreatment and adult emotional dysregulation in a low-income, urban, African-American sample: moderation by oxytocin receptor gene. Dev Psychopathol 23(2):439-452

Bradley RG, Binder EB, Epstein MP, Tang Y, Nair HP, Liu W, Gillespie CF, Berg T, Evces M, Newport DJ, Stowe ZN, Heim CM, Nemeroff CB, Schwartz A, Cubells JF, Ressler KJ (2008) Influence of child abuse on adult depression: moderation by the corticotropin-releasing hormone receptor gene. Arch Gen Psychiatry 65(2): 190-200

Buchmann AF, Holz N, Boecker R, Blomeyer D, Rietschel M, Witt SH, Schmidt MH, Esser G, Banaschewski T, Brandeis D, Zimmermann US, Laucht M (2014) Moderating role of FKBP5 genotype in the impact of childhood adversity on cortisol stress response during adulthood. Eur Neuropsychopharmacol 24(6):837-845

Byrd AL, Manuck SB (2014) MAOA, childhood maltreatment, and antisocial behavior: meta-analysis of a gene-environment interaction. Biol Psychiatry 75(1):9-17

Caspi A, McClay J, Moffitt TE, Mill J, Martin J, Craig IW, Taylor A, Poulton R (2002) Role of genotype in the cycle of violence in maltreated children. Science 297(5582):851-854

Caspi A, Sugden K, Moffitt TE, Taylor A, Craig IW, Harrington H, McClay J, Mill J, Martin J, Braithwaite A, Poulton R (2003) Influence of life stress on depression: Moderation by a polymorphism in the 5-HTT gene. Science 301(5631):386-389

Cicchetti D, Rogosch FA, Oshri A (2011) Interactive effects of corticotropin releasing hormone receptor 1 , serotonin transporter linked polymorphic region, and child maltreatment on diurnal cortisol regulation and internalizing symptomatology. Dev Psychopathol 23(4):1125-1138

Cicchetti D, Rogosch FA, Hecht KF, Crick NR, Hetzel S (2014) Moderation of maltreatment effects on childhood borderline personality symptoms by gender and oxytocin receptor and FK506 binding protein 5 genes. Dev Psychopathol 26(3):831-849

Coelho R, Viola TW, Walss-Bass C, Brietzke E, Grassi-Oliveira R (2014) Childhood maltreatment and inflammatory markers: a systematic review. Acta Psychiatr Scand 129(3):180-192

Culverhouse RC, Bowes L, Breslau N, Nurnberger JI Jr., Burmeister M, Fergusson DM, Munafo M, Saccone NL, Bierut LJ, Httlpr S, Depression C (2013) Protocol for a collaborative meta-analysis of 5-HTTLPR, stress, and depression. BMC Psychiatry 13:304

Danese A, McEwen BS (2012) Adverse childhood experiences, allostasis, allostatic load, and age-related disease. Physiol Behav 106(1):29-39

Danese A, Pariante CM, Caspi A, Taylor A, Poulton R (2007) Childhood maltreatment predicts adult inflammation in a life-course study. Proc Natl Acad Sci U S A 104(4):1319-1324

Danese A, Moffitt TE, Pariante CM, Ambler A, Poulton R, Caspi A (2008) Elevated inflammation levels in depressed adults with a history of childhood maltreatment. Arch Gen Psychiatry 65(4):409-415

De Bellis MD, Zisk A (2014) The biological effects of childhood trauma. Child Adolesc Psychiatr Clin N Am 23(2):185-222

Dong M, Anda RF, Felitti VJ, Dube SR, Williamson DF, Thompson TJ, Loo CM, Giles WH (2004) The interrelatedness of multiple 
forms of childhood abuse, neglect, and household dysfunction. Child Abuse Negl 28(7):771-784

Duncan LE, Keller MC (2011) A critical review of the first 10 years of candidate gene-by-environment interaction research in psychiatry. Am J Psychiatry 168(10):1041-1049

Feresin E (2009) Lighter sentence for murderer with 'bad genes' (2009). Nature. doi:10.1038/news.2009.1050

Frodl T, Reinhold E, Koutsouleris N, Donohoe G, Bondy B, Reiser M, Moller HJ, Meisenzahl EM (2010) Childhood stress, serotonin transporter gene and brain structures in major depression. Neuropsychopharmacology 35(6):1383-1390

Goodwin RD, Stein MB (2004) Association between childhood trauma and physical disorders among adults in the united states. Psychol Med 34(3):509-520

Grabe HJ, Wittfeld K, Van der Auwera S, Janowitz D, Hegenscheid K, Habes M, Homuth G, Barnow S, John U, Nauck M, Volzke H, Meyer zu Schwabedissen H, Freyberger HJ, Hosten N (2016) Effect of the interaction between childhood abuse and rs1360780 of the FKBP5 gene on gray matter volume in a general population sample. Hum Brain Mapp 37(4):1602-1613

Gunnar MR, Donzella B (2002) Social regulation of the cortisol levels in early human development. Psychoneuroendocrinology 27(1-2): 199-220

Halldorsdottir T, Binder EB (2017) Gene x environment interactions: From molecular mechanisms to behavior. Annu Rev Psychol 68:215. doi:10.1146/annurev-psych-010416-044053

Harris A, Seckl J (2011) Glucocorticoids, prenatal stress and the programming of disease. Horm Behav 59(3):279-289

Heim C, Binder EB (2012) Current research trends in early life stress and depression: review of human studies on sensitive periods, gene-environment interactions, and epigenetics. Exp Neurol 233(1):102-111

Heim C, Newport DJ, Mletzko T, Miller AH, Nemeroff CB (2008) The link between childhood trauma and depression: Insights from HPA axis studies in humans. Psychoneuroendocrinology 33(6):693-710

Heim C, Bradley B, Mletzko TC, Deveau TC, Musselman DL, Nemeroff CB, Ressler KJ, Binder EB (2009a) Effect of childhood trauma on adult depression and neuroendocrine function: Sex-specific moderation by $\mathrm{CRH}$ receptor 1 gene. Front Behav Neurosci 3:41

Heim C, Young LJ, Newport DJ, Mletzko T, Miller AH, Nemeroff CB (2009b) Lower CSF oxytocin concentrations in women with a history of childhood abuse. Mol Psychiatry 14(10):954-958

Holsboer F (2000) The corticosteroid receptor hypothesis of depression. Neuropsychopharmacology 23(5):477-501

Holz N, Boecker R, Buchmann AF, Blomeyer D, Baumeister S, Hohmann S, Jennen-Steinmetz C, Wolf I, Rietschel M, Witt SH, Plichta MM, Meyer-Lindenberg A, Schmidt MH, Esser G, Banaschewski T, Brandeis D, Laucht M (2016) Evidence for a sex-dependent $M A O A \times$ childhood stress interaction in the neural circuitry of aggression. Cereb Cortex 26(3):904-914

Holz NE, Buchmann AF, Boecker R, Blomeyer D, Baumeister S, Wolf I, Rietschel M, Witt SH, Plichta MM, Meyer-Lindenberg A, Banaschewski T, Brandeis D, Laucht M (2015) Role of FKBP5 in emotion processing: Results on amygdala activity, connectivity and volume. Brain Struct Funct 220(3):1355-1368

Ising M, Depping AM, Siebertz A, Lucae S, Unschuld PG, Kloiber S, Horstmann S, Uhr M, Muller-Myhsok B, Holsboer F (2008) Polymorphisms in the FKBP5 gene region modulate recovery from psychosocial stress in healthy controls. Eur J Neurosci 28(2):389-398

Jaffee SR, McFarquhar T, Stevens S, Ouellet-Morin I, Melhuish E, Belsky J (2015) Interactive effects of early and recent exposure to stressful contexts on cortisol reactivity in middle childhood. J Child Psychol Psychiatry 56(2):138-146

Karg K, Burmeister M, Shedden K, Sen S (2011) The serotonin transporter promoter variant (5-HTTLPR), stress, and depression me- ta-analysis revisited: Evidence of genetic moderation. Arch Gen Psychiatry 68(5):444-454

Kaufman J, Birmaher B, Perel J, Dahl RE, Moreci P, Nelson B, Wells W, Ryan ND (1997) The corticotropin-releasing hormone challenge in depressed abused, depressed nonabused, and normal control children. Biol Psychiatry 42(8):669-679

Keller MC (2014) Gene x environment interaction studies have not properly controlled for potential confounders: the problem and the (simple) solution. Biol Psychiatry 75(1):18-24

Kessler RC, McLaughlin KA, Green JG, Gruber MJ, Sampson NA, Zaslavsky AM, Aguilar-Gaxiola S, Alhamzawi AO, Alonso J, Angermeyer M, Benjet C, Bromet E, Chatterji S, de Girolamo G, Demyttenaere K, Fayyad J, Florescu S, Gal G, Gureje O, Haro JM, Hu CY, Karam EG, Kawakami N, Lee S, Lepine JP, Ormel J, Posada-Villa J, Sagar R, Tsang A, Ustun TB, Vassilev S, Viana MC, Williams DR (2010) Childhood adversities and adult psychopathology in the WHO world mental health surveys. Br J Psychiatry 197(5):378-385

Klengel T, Binder EB (2015) FKBP5 allele-specific epigenetic modification in gene by environment interaction. Neuropsychopharmacology 40(1):244-246

Klengel T, Mehta D, Anacker C, Rex-Haffner M, Pruessner JC, Pariante CM, Pace TW, Mercer KB, Mayberg HS, Bradley B, Nemeroff CB, Holsboer F, Heim CM, Ressler KJ, Rein T, Binder EB (2013) Allele-specific FKBP5 DNA demethylation mediates gene-childhood trauma interactions. Nat Neurosci 16(1):33-41

de Kloet ER, Joels M, Holsboer F (2005) Stress and the brain: from adaptation to disease. Nat Rev Neurosci 6(6):463-475

Labonte B, Suderman M, Maussion G, Navaro L, Yerko V, Mahar I, Bureau A, Mechawar N, Szyf M, Meaney MJ, Turecki G (2012) Genome-wide epigenetic regulation by early-life trauma. Arch Gen Psychiatry 69(7):722-731

Leeners B, Stiller R, Block E, Gorres G, Rath W (2010) Pregnancy complications in women with childhood sexual abuse experiences. J Psychosom Res 69(5):503-510

Liu D, Diorio J, Tannenbaum B, Caldji C, Francis D, Freedman A, Sharma S, Pearson D, Plotsky PM, Meaney MJ (1997) Maternal care, hippocampal glucocorticoid receptors, and hypothalamic-pituitary-adrenal responses to stress. Science 277(5332):1659-1662

Lupien SJ, McEwen BS, Gunnar MR, Heim C (2009) Effects of stress throughout the lifespan on the brain, behaviour and cognition. Nat Rev Neurosci 10(6):434-445

McCrory E, De Brito SA, Viding E (2011) The impact of childhood maltreatment: a review of neurobiological and genetic factors. Front Psychiatry 2:48

McGowan PO, Sasaki A, D'Alessio AC, Dymov S, Labonte B, Szyf M, Turecki G, Meaney MJ (2009) Epigenetic regulation of the glucocorticoid receptor in human brain associates with childhood abuse. Nat Neurosci 12(3):342-348

McQuaid RJ, McInnis OA, Stead JD, Matheson K, Anisman H (2013) A paradoxical association of an oxytocin receptor gene polymorphism: early-life adversity and vulnerability to depression. Front Neurosci 7:128

Mehta D, Klengel T, Conneely KN, Smith AK, Altmann A, Pace TW, Rex-Haffner M, Loeschner A, Gonik M, Mercer KB, Bradley B, Muller-Myhsok B, Ressler KJ, Binder EB (2013) Childhood maltreatment is associated with distinct genomic and epigenetic profiles in posttraumatic stress disorder. Proc Natl Acad Sci U S A 110(20):8302-8307

Melas PA, Wei Y, Wong CC, Sjoholm LK, Aberg E, Mill J, Schalling M, Forsell Y, Lavebratt C (2013) Genetic and epigenetic associations of MAOA and NR3C1 with depression and childhood adversities. Int J Neuropsychopharmacol 16(7):1513-1528

Mohiyeddini C, Opacka-Juffry J, Gross JJ (2014) Emotional suppression explains the link between early life stress and plasma oxytocin. Anxiety Stress Coping 27(4):466-475 
Moog NK, Buss C, Entringer S, Shahbaba B, Gillen DL, Hobel CJ, Wadhwa PD (2016) Maternal exposure to childhood trauma is associated during pregnancy with placental-fetal stress physiology. Biol Psychiatry 79(10):831-839

Mueller A, Armbruster D, Moser DA, Canli T, Lesch KP, Brocke B, Kirschbaum C (2011) Interaction of serotonin transporter genelinked polymorphic region and stressful life events predicts cortisol stress response. Neuropsychopharmacology 36(7):1332-1339

Mullins N, Power RA, Fisher HL, Hanscombe KB, Euesden J, Iniesta R, Levinson DF, Weissman MM, Potash JB, Shi J, Uher R, Cohen-Woods S, Rivera M, Jones L, Jones I, Craddock N, Owen MJ, Korszun A, Craig IW, Farmer AE, McGuffin P, Breen G, Lewis CM (2016) Polygenic interactions with environmental adversity in the aetiology of major depressive disorder. Psychol Med 46(4):759-770

Murgatroyd C, Quinn JP, Sharp HM, Pickles A, Hill J (2015) Effects of prenatal and postnatal depression, and maternal stroking, at the glucocorticoid receptor gene. Transl Psychiatry 5:e560

Myers AJ, Williams L, Gatt JM, McAuley-Clark EZ, Dobson-Stone C, Schofield PR, Nemeroff CB (2014) Variation in the oxytocin receptor gene is associated with increased risk for anxiety, stress and depression in individuals with a history of exposure to early life stress. J Psychiatr Res 59:93-100

Nemeroff CB (2016) Paradise lost: the neurobiological and clinical consequences of child abuse and neglect. Neuron 89(5):892-909

Ouellet-Morin I, Odgers CL, Danese A, Bowes L, Shakoor S, Papadopoulos AS, Caspi A, Moffitt TE, Arseneault L (2011) Blunted cortisol responses to stress signal social and behavioral problems among maltreated/bullied 12-year-old children. Biol Psychiatry 70(11):1016-1023

Ouellet-Morin I, Wong CC, Danese A, Pariante CM, Papadopoulos AS, Mill J, Arseneault L (2013) Increased serotonin transporter gene (SERT) DNA methylation is associated with bullying victimization and blunted cortisol response to stress in childhood: a longitudinal study of discordant monozygotic twins. Psychol Med 43(9):1813-1823

Palma-Gudiel H, Fananas L (2017) An integrative review of methylation at the serotonin transporter gene and its dialogue with environmental risk factors, psychopathology and 5-httlpr. Neurosci Biobehav Rev 72:190-209

Pape JC, Binder EB (2014) Psychological trauma as risk for delayed psychiatric disorders: epigenetic mechanisms. Nervenarzt 85(11):1382-1389

Peyrot WJ, Milaneschi Y, Abdellaoui A, Sullivan PF, Hottenga JJ, Boomsma DI, Penninx BW (2014) Effect of polygenic risk scores on depression in childhood trauma. Br J Psychiatry 205(2):113-119

Pierrehumbert B, Torrisi R, Laufer D, Halfon O, Ansermet F, Beck Popovic M (2010) Oxytocin response to an experimental psychosocial challenge in adults exposed to traumatic experiences during childhood or adolescence. Neuroscience 166(1):168-177

Price LH, Kao HT, Burgers DE, Carpenter LL, Tyrka AR (2013) Telomeres and early-life stress: an overview. Biol Psychiatry 73(1):15-23

Provençal N, Binder EB (2015) The effects of early life stress on the epigenome: from the womb to adulthood and even before. Exp Neurol 268:10-20

Provençal N, Suderman MJ, Guillemin C, Massart R, Ruggiero A, Wang D, Bennett AJ, Pierre PJ, Friedman DP, Cote SM, Hallett M, Tremblay RE, Suomi SJ, Szyf M (2012) The signature of maternal rearing in the methylome in rhesus macaque prefrontal cortex and t cells. J Neurosci 32(44):15626-15642

Provenzi L, Giorda R, Beri S, Montirosso R (2016) SLC6A4 methylation as an epigenetic marker of life adversity exposures in humans: a systematic review of literature. Neurosci Biobehav Rev 71:7-20

Radtke KM, Ruf M, Gunter HM, Dohrmann K, Schauer M, Meyer A, Elbert T (2011) Transgenerational impact of intimate partner violence on methylation in the promoter of the glucocorticoid receptor. Transl Psychiatry 1:e21

Radtke KM, Schauer M, Gunter HM, Ruf-Leuschner M, Sill J, Meyer A, Elbert T (2015) Epigenetic modifications of the glucocorticoid receptor gene are associated with the vulnerability to psychopathology in childhood maltreatment. Transl Psychiatry 5:e571

Rutter M, Moffitt TE, Caspi A (2006) Gene-environment interplay and psychopathology: multiple varieties but real effects. J Child Psychol Psychiatry 47(3-4):226-261

Seltzer LJ, Ziegler T, Connolly MJ, Prososki AR, Pollak SD (2014) Stress-induced elevation of oxytocin in maltreated children: evolution, neurodevelopment, and social behavior. Child Dev 85(2):501-512

Shalev I, Moffitt TE, Sugden K, Williams B, Houts RM, Danese A, Mill J, Arseneault L, Caspi A (2013) Exposure to violence during childhood is associated with telomere erosion from 5 to 10 years of age: a longitudinal study. Mol Psychiatry 18(5):576-581

Sharpley CF, Palanisamy SK, Glyde NS, Dillingham PW, Agnew LL (2014) An update on the interaction between the serotonin transporter promoter variant (5-HTTLPR), stress and depression, plus an exploration of non-confirming findings. Behav Brain Res 273:89-105

Smearman EL, Almli LM, Conneely KN, Brody GH, Sales JM, Bradley B, Ressler KJ, Smith AK (2016) Oxytocin receptor genetic and epigenetic variations: Association with child abuse and adult psychiatric symptoms. Child Dev 87(1):122-134

Smith ME (2005) Bilateral hippocampal volume reduction in adults with post-traumatic stress disorder: a meta-analysis of structural mri studies. Hippocampus 15(6):798-807

Struber N, Struber D, Roth G (2014) Impact of early adversity on glucocorticoid regulation and later mental disorders. Neurosci Biobehav Rev 38:17-37

Suderman M, Borghol N, Pappas JJ, Pinto Pereira SM, Pembrey M, Hertzman C, Power C, Szyf M (2014) Childhood abuse is associated with methylation of multiple loci in adult DNA. BMC Med Genomics 7:13

Teicher MH, Samson JA (2016) Annual research review: enduring neurobiological effects of childhood abuse and neglect. J Child Psychol Psychiatry 57(3):241-266

Trickett PK, Noll JG, Susman EJ, Shenk CE, Putnam FW (2010) Attenuation of cortisol across development for victims of sexual abuse. Dev Psychopathol 22(1):165-175

Turecki G, Meaney MJ (2016) Effects of the social environment and stress on glucocorticoid receptor gene methylation: a systematic review. Biol Psychiatry 79(2):87-96

Tyrka AR, Price LH, Gelernter J, Schepker C, Anderson GM, Carpenter LL (2009) Interaction of childhood maltreatment with the corticotropin-releasing hormone receptor gene: effects on hypothalamic-pituitary-adrenal axis reactivity. Biol Psychiatry 66(7):681-685

Tyrka AR, Ridout KK, Parade SH, Paquette A, Marsit CJ, Seifer R (2015) Childhood maltreatment and methylation of FK506 binding protein 5 gene (FKBP5). Dev Psychopathol 27(4 Pt 2):1637-1645

Vijayendran M, Beach SR, Plume JM, Brody GH, Philibert RA (2012) Effects of genotype and child abuse on DNA methylation and gene expression at the serotonin transporter. Front Psychiatry 3:55

Weaver IC, Cervoni N, Champagne FA, D'Alessio AC, Sharma S, Seckl JR, Dymov S, Szyf M, Meaney MJ (2004) Epigenetic programming by maternal behavior. Nat Neurosci 7(8):847-854

Weaver IC, Champagne FA, Brown SE, Dymov S, Sharma S, Meaney MJ, Szyf M (2005) Reversal of maternal programming of stress responses in adult offspring through methyl supplementation: altering epigenetic marking later in life. J Neurosci 25(47):11045-11054

White MG, Bogdan R, Fisher PM, Munoz KE, Williamson DE, Hariri AR (2012) FKBP5 and emotional neglect interact to predict 
individual differences in amygdala reactivity. Genes Brain Behav 11(7):869-878

Yehuda R, Daskalakis NP, Bierer LM, Bader HN, Klengel T, Holsboer F, Binder EB (2016) Holocaust exposure induced intergenerational effects on FKBP5 methylation. Biol Psychiatry 80:372. doi:10.1016/j.biopsych.2015.08.005

Zannas AS, Binder EB (2014) Gene-environment interactions at the FKBP5 locus: sensitive periods, mechanisms and pleiotropism. Genes Brain Behav 13(1):25-37
Zannas AS, Wiechmann T, Gassen NC, Binder EB (2016) Gene-stressepigenetic regulation of $F K B P 5$ : clinical and translational implications. Neuropsychopharmacology 41(1):261-274

Zimmermann P, Bruckl T, Nocon A, Pfister H, Binder EB, Uhr M, Lieb R, Moffitt TE, Caspi A, Holsboer F, Ising M (2011) Interaction of FKBP5 gene variants and adverse life events in predicting depression onset: Results from a 10-year prospective community study. Am J Psychiatry 168(10):1107-1116 